\title{
ENCARCERAMENTO E COVID19 À LUZ DA CRIMINOLOGIA FEMINISTA: A RECOMENDAÇÃO N62 DO CONSELHO NACIONAL DE JUSTIÇA COMO UM IMPULSO À EFETIVAÇÃO DE DIREITOS FUNDAMENTAIS DE MULHERES MÃES E GESTANTES PRESAS
}

\author{
Vanessa Chiari Gonçalves* \\ Jessica de Jesus Mota* \\ Juliana Horowitz*
}

Resumo: Este artigo aborda a problemática do encarceramento de mulheres mães e gestantes no contexto da pandemia da Covid19. Parte-se da pergunta: "Em que medida a Resolução 62 editada pelo Conselho Nacional de Justiça (CNJ), em meio à pandemia da Covid19, consolida-se como incentivo à conversão de prisão provisória em prisão domiciliar nos casos de mães e gestantes presas?". Mobiliza-se o arcabouço teórico da criminologia feminista e a técnica de revisão bibliográfica. O trabalho aponta que a Recomendação $n^{\circ} 62$ do CNJ é um impulso à efetivação de medidas de desencarceramento previstas no ordenamento brasileiro para mulheres mães e gestantes presas.

Palavras-chave: Covid19; Encarceramento feminino; Habeas Corpus 143.641/18; Medidas alternativas; Recomendação ${ }^{\circ} 62$ do Conselho Nacional de Justiça

\section{INCARCERATION,COVID19 AND FEMINIST CRIMINOLOGY : THE RECOMMENDATION N ${ }^{\circ} 62$ OF THE NATIONAL COUNCIL OF JUSTICE AS AN IMPULSE TO THE EFFECTIVENESS OF FUNDAMENTAL RIGHTS OF MOTHERS AND PREGNANT WOMEN.}

\begin{abstract}
"Doutora em Direito pela Universidade Federal do Paraná (2011), tendo realizado estágio doutoral (2010) junto ao Centro de Ciências Jurídicas da Universidade de Bolonha com a supervisão de Massimo Pavarini. Iniciou sua carreira docente em 2001 na Universidade Federal do Rio Grande. Exerceu a função de conselheira penitenciária do Estado do Rio Grande do Sul (2003-2007). Atualmente é docente permanente do Programa de Pós-Graduação em Direito da Universidade Federal do Rio Grande do Sul e professora adjunta de direito penal e criminologia do Departamento de Ciências Penais da Universidade Federal do Rio Grande do Sul. É pesquisadora líder do Núcleo de Pesquisa em Direito Penal e Criminologia (NUPECRIM), da UFRGS/CNPq. Integra o Laboratório de Pesquisa Empírica em Direito (LaPED) da UFRGS, o Instituto Nacional de Ciência e Tecnologia Forense (INCT Forense), na condição de líder de laboratório associado, e The Carceral Studies Working Group (CSWG), Email: vanessachiarigoncalves@gmail.com

"Mestranda no Programa de Pós-Graduação em Direito da Universidade Federal do Rio Grande do Sul (UFRGS), bolsista CAPES. Compondo, atualmente, o grupo de pesquisa Núcleo de Pesquisa em Direito Penal e Criminologia UFRGS/CNPq. Bacharela em Direito pela Universidade Federal de Pelotas (UFPEL). Email: jejemota01@gmail.com

"Mestranda no Programa de Pós-Graduação em Direito da Universidade Federal do Rio Grande do Sul (UFRGS), bolsista CAPES, com período de pesquisadora visitante na Universidade de Wisconsin-Madison, Estados Unidos. Bacharela em Direito pela UFRGS. Integrante do Núcleo de Pesquisas em Direito Penal e Criminologia UFRGS/CNPq.Email: julianaghorowitz@gmail.com
\end{abstract}


Abstract: This article addresses the issue of incarcerated mothers and pregnant women in the context of Covid19. It starts with the question: "To what extent does Resolution 62 issued by the National Council of Justice (CNJ), in the midst of the Covid19, consolidate itself as an incentive to convert from provisional prison to house arrest in cases of incarcerated mothers and pregnant women?". The theoretical framework of feminist criminology and the literature review are mobilized. The work points out that CNJ Recommendation 62 is an impetus for the implementation of alternative measures provided for Brazilian mothers and pregnant women in prison.

Keywords: Alternative Measures; Covid19; Female Incarceration; Habeas Corpus 143.641/18; Recommendation 62 of the National Council of Justice

\section{INTRODUÇÃO}

A realidade vivida por mulheres mães e gestantes, no sistema prisional brasileiro, é atravessada por diversas violações de direitos fundamentais. Não obstante a previsão constitucional no sentido de que a privação de liberdade deve se concretizar de modo humanitário, a falência do sistema carcerário nacional já foi apontada. Inclusive, essa conjuntura foi atestada pelo Supremo Tribunal Federal (STF) no julgamento da ADPF 437, em que foi reconhecido o "estado de coisas inconstitucional" dos presídios no país.

Nesse cenário, a temática referente às mulheres gestantes e mães ganhou relevo a partir de decisão paradigmática no Habeas Corpus (HC) 143.631/2018, julgado pelo STF.. Por meio dessa decisão, foi concedida a possibilidade de conversão de prisão provisória em prisão domiciliar para mulheres mães e gestantes, que atendessem aos requisitos dispostos, ganhando força o debate sobre direitos fundamentais de mulheres presas no contexto nacional. $\mathrm{Na}$ esteira daquilo que foi proposto pelo referido $H C$, em dezembro de 2018, foi publicada a Lei 13.769/2018 que alterou o Código de Processo Penal, inserindo os artigos 318-A e 318-B.

No entanto, apesar da decisão do STF e da posterior positivação legislativa da implementação de medidas alternativas à privação de liberdade convencional das mulheres, o relatório do Instituto Terra, Trabalho e Cidadania (ITTC) (2019) desvelou a realidade de que a legislação não é aplicada em todos os casos aos quais se amolda. Pelo contrário: há muitas mulheres que atendem aos requisitos dispostos pela legislação, a quem não foi substituída a prisão preventiva por prisão domiciliar.

Imbrica-se essa realidade à atual situação de pandemia global vivida em razão do novo Coronavírus. Por certo, a crise sanitária não só traz novas problemáticas, mas potencializa as já existentes e escancara as falências do sistema prisional brasileiro. Diante da 


\section{ENCARCERAMENTO E COVID19 À LUZ DA CRIMINOLOGIA FEMINISTA: A RECOMENDAÇÃO \\ №62 DO CONSELHO NACIONAL DE JUSTIÇA COMO UM IMPULSO À EFETIVAÇÃO DE DIREITOS \\ FUNDAMENTAIS DE MULHERES MÃES E GESTANTES PRESAS}

necessidade de isolamento social e de diretrizes de prevenção, foi publicada a Recomendação $n^{\circ} 62$ do Conselho Nacional de Justiça (CNJ), com o fim de endereçar medidas de saúde ao sistema prisional e socioeducativo. Tal Recomendação expõe a necessidade de diminuição da população prisional, apontando como um caminho a reavaliação de prisões provisórias, especialmente para os casos de mães com filhos de até 12 anos e gestantes.

A presente investigação, portanto, responde a seguinte pergunta central: Em que medida a Recomendação 62, editada pelo Conselho Nacional de Justiça, em meio à pandemia da Covid19, consolida-se como incentivo à conversão de prisão provisória em prisão domiciliar nos casos de mães e gestantes, garantindo, assim, os direitos fundamentais dessas mulheres? O recorte da pesquisa, envolvendo apenas a prisão provisória, justifica-se porque as regras aplicadas às prisões cautelares são equivalentes às do regime fechado de cumprimento de pena. Além disso, o último INFOPEN Mulheres demonstrou que $45 \%$ das mulheres presas no Brasil, em Junho de 2016, não haviam sido ainda julgadas e condenadas. Salienta-se que na primeira edição do INFOPEN Mulheres, com dados referentes a Junho de 2014, 30,1\% das mulheres encarceradas não tinham condenação. Esses dados demonstram um crescimento significativo do percentual de mulheres privadas de liberdade provisoriamente (INFOPEN, 2018).

O artigo está dividido em três partes. No primeiro momento, por meio da técnica de revisão bibliográfica, mobiliza-se o arcabouço teórico da Criminologia Feminista como lente de análise para a compreensão do HC 143.641, julgado pelo STF, e do panorama legislativo relacionado aos direitos fundamentais de mulheres mães e gestantes presas. Em seguida, examina-se a Recomendação Conjunta $n^{\circ} 62$ do Conselho Nacional de Justiça (CNJ), expondo os atravessamentos da pandemia no sistema de justiça criminal. Finalmente, propõe-se compreender tal Recomendação como impulso à efetiva conversão de prisão provisória em domiciliar para mulheres mães e gestantes presas, atentando-se à necessidade de efetivação dos direitos fundamentais dessa população prisional.

\section{DO FEMINISMO JURÍDICO À CRIMINOLOGIA FEMINISTA COMO LENTE DE ANÁLISE DO ENCARCERAMENTO FEMININO}


O crescimento da população feminina encarcerada no Brasil é um fato que requer análise complexa e urgente, uma vez que houve o crescimento de $656 \%$ da população carcerária feminina entre os anos 2000 e 2016. Neste cenário, a mulher negra está majoritariamente presente, compondo $67 \%$ da população carcerária feminina nos presídios brasileiros (INFOPEN, 2018).

Diante da preocupação causada pelo hiperencarceramento feminino, visualiza-se a necessidade de compreender a complexidade desse fenômeno por uma perspectiva diferente daquela comumente construída pelo Direito. Uma ótica que evidencie o sufocamento das mulheres por uma hierarquia masculina (naturalizada pelo Direito), trazendo a possibilidade de um estudo emancipador na questão de gênero. Para isso, primeiramente, vale ressaltar os importantes estudos de autoras como Carol Smart, Frances Olsen, Sandra Harding e Catherine Mackinnon ${ }^{1}$ que, em síntese, tratam de um feminismo sociojurídico que questiona o Direito e põe em cheque a sua pretensa neutralidade.

Harding estuda a construção das epistemologias feministas e as divide em: empirismo feminista, ponto de vista feminista (standpoint) e feminismo pós-moderno. No empirismo feminista acredita-se que a ciência não é neutra e sim masculina, mas com a aplicação da metodologia correta (ou seja, verdadeiramente, não sexista) essa realidade se transformaria. A teoria do standpoint propõe a construção da ciência a partir do ponto de vista dos grupos oprimidos, os quais têm a possibilidade de formular discursos potencialmente mais críticos do que os dominantes. Por fim, o feminismo pós-moderno questiona qualquer tentativa de universalidade e totalidade dentro da construção do conhecimento (MENDES, 2017, p. 78-81). A autora tenta, assim, compreender a ciência como um todo, auxiliando a tecer uma epistemologia feminista. Já Carol Smart classifica as discussões trazidas ao campo jurídico pelo feminismo discutindo o que é o Direito e estabelecendo determinados paradigmas, tais como: "o direito é sexista", o "direito é masculino", "o direito têm gênero".

\footnotetext{
${ }^{1}$ Carol Smart é uma socióloga e ativista feminista britânica, formada pela Universidade de Sheffield, que dedicou seus estudos às questões de gênero também no campo da Criminologia, sendo um de suas produções mais importantes nessa área o livro Women, crime, and criminology: a feminist critique (1977).

Frances Olsen é professora de direito na UCLA e membro notável da escola de Teoria Legal Feminista. Escreveu o livro Feminist Legal Theory (1983).

Sandra Harding é uma filósofa estadunidense reconhecida por seus estudos sobre a teoria feminista, pós-colonialidade, epistemologia entre outros. Foi a criadora do conceito do standpoint theory. Autora do livro The Science Question in Feminism (1986).

Catherine Mackinnon atualmente leciona direito na Universidade de Michigan, realizou grandes trabalhos na luta contra a pornografia. Autora do livro Feminism Unmodified: Discourses on Life and Law (1987).
} 


\section{ENCARCERAMENTO E COVID19 À LUZ DA CRIMINOLOGIA FEMINISTA: A RECOMENDAÇÃO \\ №62 DO CONSELHO NACIONAL DE JUSTIÇA COMO UM IMPULSO À EFETIVAÇÃO DE DIREITOS \\ FUNDAMENTAIS DE MULHERES MÃES E GESTANTES PRESAS}

Dentro dessa última categoria, estuda o Direito como estratégia de criação do próprio gênero (SMART, 1992, p. 36-40) ${ }^{2}$.

Assim, quando se diz que o Direito é sexista é devido ao fato de o mesmo estabelecer uma diferenciação entre homens e mulheres, colocando as mulheres em desvantagem, uma vez que foram dispostos "menos recursos materiais no matrimônio ou no divórcio, negou igualdade de oportunidades e não reconheceu os danos causados às mulheres "(SMART, 1992, p. 36). Nessas situações, o rótulo de sexista constituiu um meio de desafiar a ordem normativa do direito e dá nova interpretação a essas práticas, colocando-as como indesejáveis e inaceitáveis (SMART, 1992, p. 36). A segunda afirmação é de que o Direito é masculino, destacando que a suposta neutralidade e a objetividade celebradas nesse ramo do conhecimento nada mais são do que valores masculinos que foram considerados como universais (SMART, 1992, p. 37). ${ }^{3}$

A terceira afirmação, de que o Direito tem gênero, demonstra que o discurso jurídico incorpora a divisão sexual e não concebe um sujeito cujo atributo definitório não seja o gênero (SMART, 1992, p. 40). E, por fim, o Direito como estratégia de criação de gênero aparece quando se reconhece o campo jurídico como tecnologia de gênero, que não apenas oprime a mulher mas produz diferenças de comportamento e de identidade. (SMART, 1992, p. 49).

A partir de tais afirmações, as teóricas do feminismo sociojurídico da década de 80 nos permitem entender o paradigma de gênero na construção do direito e pensar os efeitos disso na esfera penal, em especial no sistema carcerário e no estudo da criminologia. Em decorrência disso, com o movimento de mulheres e o refinamento dos estudos em criminologia feminista, foi-se aperfeiçoando o entendimento de como o Direito está inserido numa estrutura patriarcal e capitalista (WEIGERT; CARVALHO, 2019).

\footnotetext{
2 "O direito é sexista": essa visão corresponde à primeira onda do feminismo, também chamada como o feminismo da igualdade (SILVA, 2018, p. 88).

"O direito é masculino": corresponde a segunda onda do feminismo (feminismo da diferença ou feminismo cultural). Teve muita força entre as décadas de 1960 e 1980 e ainda é muito utilizado na atualidade. A segunda onda fez duras críticas ao direito por entendê-lo como instrumento da dominação patriarcal (SILVA, 2018, p. 88).

"O direito tem gênero": decorrente da terceira onda do feminismo, entende o direito como "tecnologia do gênero", isto é, como algo que tanto constrói o gênero como é construído por ele. Também inclui os diversos marcadores sociais (SILVA, 2018, p. 88).

${ }^{3}$ Aqui , Carol Smart corrobora com as ideias de Katherine Mackinnon de perceber o discurso masculino como universalizante.
} 
Nessa senda, Angela Davis, em seu livro “Estarão as prisões obsoletas?” (2006), aborda, com maestria, a centralidade do gênero na punição estatal, visto que apesar dos homens constituírem a ampla maioria dos prisioneiros do mundo, as mulheres dentro das prisões são duplamente ou triplamente oprimidas. Para isso, a autora demonstra a categoria de "desvio" na qual a mulher é colocada, aproximando-a da falta de moralidade e da loucura, além de estar submetida a um controle total de sua sexualidade. Ademais, o enquadramento da criminalidade também se dá de maneira racializada, visto que a criminalidade é atribuída majoritariamente às mulheres negras. Dessa forma, segundo Angela:

Quando consideramos o impacto da classe e da raça, podemos dizer que, para mulheres brancas e ricas essa equalização tende a servir como evidência de transtornos emocionais e mentais, mas para as mulheres negras e pobres indica a criminalidade. (DAVIS, 2012, p 73).

A mesma autora, ao citar o relatório de Direitos Humanos de 1996 sobre o abuso de mulheres nas prisões dos Estados Unidos, observa que a combinação do racismo e da misoginia mantém todas as suas terríveis consequências nas prisões femininas (2012, p. 89). Assim, partindo desse tripé raça, classe e gênero, apresentado por Davis desde um ponto de vista interseccional ${ }^{4}$, é necessário observar a condição brasileira.

No Brasil, o racismo tem se mostrado fator decisivo, tanto para as mulheres, como para os homens, na determinação de quem será preso ou não. Nesse viés, Juliana Borges expõe a necessidade e a emergência do Feminismo Interseccional na luta por transformações sociais e, especialmente, ao se tratar do encarceramento feminino (2019, p. 93-94). Para a autora, o Brasil é um país colonizado, edificado com base na escravidão e na morte de milhares de pessoas. Entretanto, na formação da cultura nacional, se faz presente o chamado "mito da democracia racial" que vela as inúmeras discriminações presentes na estrutura social (racista e misógina) do país, bem como em todas as suas instituições, inclusive no sistema judiciário (BORGES, 2019, p. 17-29).

A diversidade nacional não se deu de forma pacífica, mas sim baseada na escravidão que tem influência direta nos dias atuais, tanto para opressão de raça quanto de gênero. A desigualdade social e a marginalização da camada mais pobre da população criou, como diria Jesse de Souza (2003), os considerados "subcidadãos", aqueles que possuem poucos direitos

${ }^{4}$ Termo cunhado pela professora americana e defensora de direitos civis Kimberlé Williams Crenshaw. A teoria interseccional examina os sistemas sobrepostos de opressão e discriminação aos quais as mulheres estão sujeitas (raça, classe e gênero). 


\section{ENCARCERAMENTO E COVID19 À LUZ DA CRIMINOLOGIA FEMINISTA: A RECOMENDAÇÃO \\ №62 DO CONSELHO NACIONAL DE JUSTIÇA COMO UM IMPULSO À EFETIVAÇÃO DE DIREITOS \\ FUNDAMENTAIS DE MULHERES MÃES E GESTANTES PRESAS}

garantidos, são extremamente explorados e "etiquetados" pelo Direito Penal como criminosos (BARATTA, 1999, p. 21)

Nesse contexto, é possível compreender a questão de gênero e raça como formas de opressão que estruturam o sistema penal. Outro fato que contribui para a necessidade de um estudo pautado no gênero é de que dentre a população carcerária feminina brasileira, segundo dados do Departamento Penitenciário Nacional (INFOPEN, 2018), cerca de 74\% são mães. Essas mulheres vivem a maternidade num contexto controlado e hierarquizado, devendo cuidar dos seus filhos sem o poder decisório e a liberdade de ação necessária para fazê-lo, demonstrando controle e violando até mesmo seus direitos reprodutivos (DIUANA, 2016).

Ademais, é latente a violação de direitos humanos presentes, em especial às garantias descritas pelo Tratado Internacional de Bangkok ${ }^{5}$ (MPPR, 2019). A separação entre as mães presas e seus filhos já aparecia como um grave problema decorrente da política de encarceramento em massa adotada no Brasil. Na pandemia de Covid19, entretanto, a situação se agravou uma vez que o Estado não conseguiu ser ágil o suficiente para assegurar o direito de visita por meio virtual em grande parte das penitenciárias femininas do país.

Diante desse contexto, os saberes criminológicos são importantes suportes para se pensar a questão do encarceramento e de suas consequências. Soraia Mendes (2017) refere que foi somente na década de 80 que se começou a tratar as questões de gênero com maior relevância, a partir do desenvolvimento feminista da criminologia crítica, passando "a ser interpretado o sistema de justiça criminal pelo viés macrossociológico, nos termos das categorias patriarcado e gênero" (MENDES, 2017, p. 63). Para a autora, mesmo a criminologia crítica apresenta seus limites quando se trata do paradigma de gênero (MENDES, 2017, p. 74). As mulheres foram objeto de estudo secundário dentro de diferentes

${ }^{5}$ Regras aprovadas pela Assembleia Geral da ONU, em 2010, com diretrizes para o tratamento de mulheres presas e medidas não privativas de liberdade para mulheres infratoras. Disponível em: https://www.cnj.jus.br/wp-content/uploads/2019/09/cd8bc11ffdcbc397c32eecdc40afbb74.pdf 
correntes da criminologia, desde Cesare Lombroso $^{6}$, mas o paradigma de gênero não chegou a ser estudado e compreendido ${ }^{7}$.

Por sua vez, Juliana Borges (2018, p. 92-93) entende que o sistema criminal teve apenas ações diversas na aplicação das punições, devendo-se levar em conta o patriarcado como estrutura que determinou essa diferenciação, com a separação das esferas públicas e privadas mencionadas inicialmente neste artigo. Para a autora, isso enseja uma dupla invisibilidade às mulheres no cárcere: serem prisioneiras e mulheres. A criminologia feminista, por sua vez, propõe a "construção de um referencial epistemológico, sem abrir mão da crítica ao Direito Penal, que trabalhe os processos de criminalização e vitimização das mulheres sob a perspectiva de gênero", pois o poder punitivo se consolida em relação às mulheres a partir de um conjunto de sujeições (MENDES, 2017, p. 155). Dessa maneira, Mendes (2017, p. 157) refere que:

Adotar o ponto de vista feminista significa um giro epistemológico, que exige partir
da realidade vivida pelas mulheres (sejam vítimas, rés ou condenadas) dentro e fora
do sistema de justiça criminal. Penso que aí está o objetivo maior de uma
criminologia feminista, que não tem como ser concebida como "um novo
ingrediente" nos marcos do que já foi produzido por outras criminologias. (grifo
nosso).

Considerando as categorias observadas em estudos Criminológicos Feministas, somadas à interseccionalidade dos marcadores sociais de classe, raça e gênero, questiona-se como o Direito têm lidado com a criminalidade feminina. Elena de Larrauri (1994) afirma que o Direito Penal cria uma imagem da mulher, construindo estereótipos e reproduzindo discriminações. No mesmo sentido, Zaffaroni pondera que, de acordo com o discurso feminista, foi por meio deste controle estatal que o poder operou o controle social punitivo, construindo as mais diversas discriminações estruturais para a manutenção de tal poder (ZAFFARONI, 1992). Nesse sentido, é possível pensar que:

[...] para compreender o etiquetamento feminino, seja como autora, seja como vítima, é preciso compreender também como historicamente o poder patriarcal e

${ }^{6}$ A fundação da criminologia moderna pode ser creditada ao médico italiano Cesare Lombroso. Para ele a origem do crime é individual (etiologia) devendo se estudar o delinquente, valendo-se de um determinismo biológico que fundamentou a escola positivista. $\mathrm{Na}$ mesma linha do livro do autor chamado O homem deliquente, Lombroso escreveu a "La Donna Deliquente". Segundo o autor, as mulheres seriam amorais e isso as fazia cair na prostituição, o outro tipo de criminosas existententes seriam aquelas com características físicas e comportamentos masculinos (MENDES, 2017, p. 37-48).

7 O nascimento da criminologia crítica na década de 70 teve na obra de Georg Rushe e Otto Kirchheimer um de seu pilares. Para os autores o cárcere torna uma necessidade do capitalismo industrial, tendo seus debates centrados na categoria de classe social (MENDES, 2017, p. 55-57). 
poder punitivo articularam-se para sua custódia pela família, na sociedade e pelo Estado (MENDES, 2017, p. 16).

Evidencia-se, assim, a necessidade de olhar a questão das mulheres mães e gestantes no cárcere com as lentes de uma criminologia feminista, pautada no enfrentamento do machismo e do racismo presentes na estrutura social. Um exemplo disso é a Lei da Primeira Infância (Lei n. 13.257/2016) que possibilitou a concessão da prisão domiciliar em substituição à prisão provisória, tornando possível a convivência da mãe com a criança em ambiente externo à prisão. Entretanto, a sua implementação não ocorreu da maneira esperada:

Era de se esperar que, após a entrada em vigor da Lei 13.257/2016, mediante a qual foi alterado o Código de Processo Penal para possibilitar a substituição da prisão preventiva por domiciliar de mulheres mães de crianças menores de 12 anos, houvesse algum câmbio no sentido da diminuição do número de mulheres cautelarmente aprisionadas em unidades prisionais. Entretanto, não foi possível perceber nada de expressivo no quadro caótico que delineei aqui (MENDES, 2020, p. 152-153).

Mesmo assim, a aplicação da Lei foi importante para que, posteriormente, a Lei n. 13.769, de 18 de dezembro de 2018, que veio ratificar a decisão do Habeas Corpus n. 143.641/SP em 20 de fevereiro de 2018, acrescentasse os artigos 318-A e 318-B no CPP, cuja principal mudança foi a de permitir a substituição da prisão preventiva por prisão domiciliar no caso de mulheres gestantes, mães ou responsáveis por crianças ou pessoas com deficiência (MPPR, 2019). A lei ampliou o rol de mulheres beneficiadas e determinou certos requisitos (MPPR, 2019).

Além disso, o referido diploma legal estabeleceu um critério objetivo para a substituição da prisão preventiva por prisão domiciliar, já que artigo 318 do CPP dizia que a prisão "poderá ser substituída", o que abria margem para a escolha subjetiva do magistrado em substituir ou não a prisão preventiva por domiciliar. Agora, com a Lei n. 13.769/18, tornou-se critério objetivo, evitando a possibilidade do juiz afastar sua aplicação (MPPR, 2019).

Entretanto, estudos do Instituto Terra, Trabalho e Cidadania (ITTC) de 2019, revelam que há certa resistência dos Tribunais na aplicação da prisão domiciliar. Inicialmente, o relatório apresenta os critérios objetivos e subjetivos dos requisitos presentes no $\mathrm{HC}$ 143.641/SP e, posteriormente, na Lei 13.769/18. Pode-se dizer que os critérios objetivos são aqueles que impõem a aplicação da prisão domiciliar para mães de crianças com até 12 anos, ou com deficiência, e para gestantes. Já os critérios subjetivos aparecem nas situações em que se pode negar a prisão domiciliar, que seriam "situações excepcionalíssimas". Tais 
excepcionalidades dependem do entendimento de cada magistrado ou magistrada (ITTC, 2019, p. 37). Assim, segundo as pesquisas efetuadas no Fórum Criminal da Barra Funda ${ }^{8}$

Houve determinação da liberdade provisória em 65 desses 120 casos, o que representa 54,2\%. Das 55 mulheres restantes, 45,8\% de 120 tiveram decretada a sua prisão preventiva. Contudo, destas, somente 9 tiveram a prisão preventiva convertida em prisão domiciliar, sendo que em 46 casos, a conversão foi negada. Isso significa que, das 55 mães de crianças menores de 12 anos ou com deficiência, gestantes e/ou imprescindíveis aos cuidados de outros que tiveram a prisão decretada e poderiam tê-la substituída pela prisão domiciliar, 83,6\% não tiveram a medida aplicada (grifo nosso) (ITTC, 2019, p. 39).

A partir dessas pesquisas, questiona-se a real efetivação das medidas alternativas para as mulheres mães e gestantes, podendo-se refletir sobre como as decisões estudadas são um espelho da visão estereotipada que a sociedade tem em relação a essas mulheres. Assim, é necessário analisar tal contexto a partir de um olhar interseccional e, somente com a utilização de estudos criminológicos feministas, pode-se entender com profundidade e qualidade a real situação em que as mulheres encarceradas estão inseridas.

Assim, diante do cenário da pandemia da Covid19, é possível visualizar as consequências devastadoras na vida de mulheres já tão marginalizadas e invisibilizadas. A promessa de cumprimento de pena de forma humanizada, conforme preconiza o art. 5, incisos XLVII (vedação de penas indignas) e XLIX (proteção da integridade do preso) da Constituição Federal, já não se concretizava mesmo antes da pandemia. Agora, com os atravessamentos gerados pelo novo vírus, é imperioso que se atente aos direitos fundamentais dessas mulheres, tornando-se ainda mais urgente a necessidade de aplicação de medidas alternativas à privação de liberdade de mães e gestantes encarceradas.

\section{A RECOMENDAÇÃO No 62 DO CNJ COMO EFETIVAÇÃO DE DIREITOS FUNDAMENTAIS DE MULHERES MÃES E GESTANTES PRESAS.}

A Organização Mundial da Saúde definiu, em 30 de janeiro de 2020, a situação de Emergência de Saúde Pública de Importância Internacional causada pelo surto do novo Coronavírus (FOLHA INFORMATIVA, 2020). Em 11 de março de 2020, foi declarada situação de pandemia pelo mesmo órgão ${ }^{9}$. No Brasil, em 17 de março de 2020, foi publicada a

\footnotetext{
${ }^{8}$ Em tal pesquisa, foram acompanhadas 201 mulheres em audiências de custódia, sendo 120 delas identificadas como possíveis casos em que caberia o direito à prisão domiciliar (ITTC, 2019).

${ }^{9}$ Disponível em: https://www.unasus.gov.br/noticia/organizacao-mundial-de-saude-declara-pandemia-decoronavirus. Acesso em: 22 mai 2020.
} 


\title{
ENCARCERAMENTO E COVID19 À LUZ DA CRIMINOLOGIA FEMINISTA: A RECOMENDAÇÃO \\ №62 DO CONSELHO NACIONAL DE JUSTIÇA COMO UM IMPULSO À EFETIVAÇÃO DE DIREITOS \\ FUNDAMENTAIS DE MULHERES MÃES E GESTANTES PRESAS
}

Recomendação ${ }^{\circ} 62$ do Conselho Nacional de Justiça (CNJ), com diretrizes aos Tribunais e magistrados de medidas preventivas a serem tomadas no âmbito dos sistemas de justiça penal e socioeducativo. Tal Recomendação destaca o agravamento da possibilidade de contágio pelo novo vírus em estabelecimentos prisionais,

\begin{abstract}
tendo em vista fatores como a aglomeração de pessoas, a insalubridade dessas unidades, as dificuldades para garantia da observância dos procedimentos mínimos de higiene e isolamento rápido dos indivíduos sintomáticos, insuficiência de equipes de saúde, entre outros, características inerentes ao "estado de coisas inconstitucional" do sistema penitenciário brasileiro reconhecido pelo Supremo Tribunal Federal na Arguição de Descumprimento de Preceito Fundamental no 347. (CNJ, 2020, s/p)
\end{abstract}

Essa Recomendação aponta para as precariedades das unidades prisionais, demarcado por "aglomerações de pessoas" e pela "insalubridade das unidades". De fato, conforme pontuam Bastos e Krell (2017, p. 307) o estado de coisas inconstitucional ${ }^{10}$ "vem ao encontro dessa pretensão política da constituição em efetivar direitos fundamentais como último recurso para se evitar maiores falhas estruturais e omissões institucionais". Assim, o reconhecimento dessa situação, frente a um sistema prisional que viola direitos fundamentais de pessoas presas diariamente, é imperioso para que se analise a problemática com a complexidade devida.

Nesse sentido, a exigência de que os direitos fundamentais sejam priorizados e efetivados vai ao encontro do que prevê a referida Recomendação, que destaca a necessidade de efetiva promoção dos direitos à saúde da pessoa presa, especialmente no contexto de pandemia. Com isso, o texto normativo pretende dar efetividade ao que está previsto na Constituição Federal de 1988, que, no artigo $5^{\circ}$, inciso XLIX, garante à pessoa presa o respeito à integridade física e moral. Nessa seara, em inúmeros dispositivos, a Recomendação atenta para a população prisional pertencente aos grupos de risco, compostos, dentre outras pessoas, por gestantes.

Especificamente quanto a gestantes e mães, foco deste artigo, no art. $4^{\circ}$, o documento recomenda a reavaliação de prisões provisórias, com fulcro no art. 316 do CPP, "priorizadose: a) mulheres gestantes, lactantes, mães ou pessoas responsáveis por criança de até doze

${ }^{10}$ Segundo Bastos e Krell (2017),premissas da teoria do Estado de Coisas Inconstitucional se amoldam à realidade brasileira. Oriunda da Corte Constitucional Colombiana, três pressupostos são necessários para a consolidação de tal estado, quais sejam, uma realidade de violação sistemática de direitos fundamentais de elevado contingente populacional; tal situação inconstitucional deve ser correlacionada a omissões e ações estatais sistêmicas; por fim, em razão de tamanhas falhas estruturais, a correção ou solução da problemática requer atuação de diversos órgãos. Ainda, nas palavras dos autores, "interpretando a teoria colombiana para a realidade prisional brasileira, percebe-se que seus pressupostos são cumpridos." (BASTOS; KRELL, 2017, p. $303)$. 
anos ou por pessoa com deficiência" (CNJ, 2020, s/p). No que tange à execução penal, a recomendação propõe, no art. $5^{\circ}$, que sejam consideradas medidas, nos termos da súmula vinculante $\mathrm{n}^{\circ} 56$ do Supremo Tribunal Federal ${ }^{11}$, a concessão de saída antecipada dos regimes fechado e semiaberto, também devendo ser priorizadas "mulheres gestantes, lactantes, mães ou pessoas responsáveis por criança de até 12 anos ou por pessoa com deficiência" (CNJ, $2020, \mathrm{~s} / \mathrm{p})^{12}$.

Justamente, é nesse ponto que a Recomendação Conjunta do CNJ se encontra com as mudanças legislativas recentes, referentes às mulheres mães e gestantes presas. Veja-se que a Recomendação atenta para a necessidade de reavaliações de prisões provisórias, no mesmo tom do que já vinha sendo decidido pelo STF e, posteriormente, positivado na legislação.. Em verdade, a crise do novo Coronavírus (re)inventa e escancara problemáticas já existentes, agora potencializadas, no que tange à violação de direitos fundamentais da população feminina encarcerada.

Seguindo a cronologia dos principais acontecimentos na legislação brasileira, consoante relatório do Instituto Terra, Trabalho e Cidadania (2019, p. 21), foi aprovado, em 08 de março de 2016, o Marco Legal da Primeira Infância (Lei n ${ }^{\circ}$ 13.257/16) que alterou os artigos 6 , 185, 304 e 318 do Código de Processo Penal. Em 09 de maio de 2017, foi impetrado o Habeas Corpus Coletivo 143.641 no Supremo Tribunal Federal pelo o Coletivo de Advocacia em Direitos Humanos (CADHu) e pela Defensoria Pública da União (DPU) "em nome de todas as mulheres presas provisoriamente que se encaixam nos critérios de aplicação da prisão domiciliar instituídos pelo Marco Legal.” (ITTC, 2019, p. 17). Em 20 de fevereiro de 2018, houve a concessão do habeas corpus "em nome de todas as mulheres presas grávidas e mães de crianças com até 12 anos de idade, exceto em casos de crime cometido com violência ou grave ameaça, crime contra descendentes e "situações excepcionalíssimas.” (ITTC, 2019, p. 22). Por fim, em 19 de dezembro de 2018, foi publicada

\footnotetext{
${ }^{11}$ É interessante observar que em pesquisa empírica realizada na Universidade Federal do Rio Grande do Sul, a prisão domiciliar com monitoramento eletrônico demonstrou ser uma fator de redução da possibilidade de reincidência quando comparada ao cumprimento de pena em regime semiaberto convencional (GONÇALVES, 2018).

${ }^{12}$ Frisa-se que a Recomendação do CNJ foi reforçada pela Resolución 1/2020, publicada pela Comisión Interamericana de Derechos Humanos (CIDH), em 10 de abril de 2020, documento que também prevê medidas específicas para pessoas privadas de liberdade, com prioridade para mulheres mães e gestantes presas. Na mesma linha do exposto pelo CNJ, a CIDH refere que devem ser tomadas medidas a fim de evitar a superlotação carcerária, com a possibilidade de reavaliação de casos de prisão preventiva com possibilidade de conversão para medidas alternativas à privação de liberdade, dando especial prioridade a casos de mulheres grávidas e lactantes (CIDH, 2020).
} 


\section{ENCARCERAMENTO E COVID19 À LUZ DA CRIMINOLOGIA FEMINISTA: A RECOMENDAÇÃO \\ №62 DO CONSELHO NACIONAL DE JUSTIÇA COMO UM IMPULSO À EFETIVAÇÃO DE DIREITOS \\ FUNDAMENTAIS DE MULHERES MÃES E GESTANTES PRESAS}

a nova lei $\mathrm{n}^{\mathrm{o}}$ 13.769/18 que alterou o Código de Processo Penal (CPP) e inseriu os artigos 318-A e 318-B.

Veja-se que a previsão de aplicação de prisão domiciliar teve início no julgamento do HC supracitado, e tornou-se positivada desde a efetiva integração dos dispositivos no CPP. Não obstante tal movimento legislativo, o relatório do ITTC (2019) demonstra que tais direitos não se efetivaram por diversas razões, especialmente sob a justificativa de situações "excepcionalíssimas", no julgamento dos casos concretos, pelos magistrados e magistradas.

No estudo, verificou-se que a negativa de concessão da prisão domiciliar utilizou como argumento o critério objetivo de ter cometido crime com grave ameaça ou contra descendentes apenas oito vezes, no restante utilizou de critérios subjetivos para justificar a decisão. A partir da análise das decisões, tornou-se evidente o caráter estigmatizante das meamas, visto que declararam, por exemplo: "que a maternidade é incompatível com o crime e/ou com o uso de drogas, além de também alegarem que há ausência de comprovação da maternidade ou de suporem que outros podem cuidar dos filhos.” (ITTC, 2019, p. 42).

Esse tipo de interpretação ocorre porque a mulher criminosa comete um duplo desvio ao contrariar as regras penais e os papéis sociais de gênero. Dessa maneira, os atores presentes no estudo descrito acima reproduzem estereótipos que contribuem para a construção de um sistema penal cada vez mais opressor, como exposto por Elena de Larrauri (1994). Tal fato desvela o que Smart (1992) já dizia: o direito é sexista, o direito é masculino, o direito têm gênero.

Percebe-se, assim, que, não obstante os critérios objetivos criados para a conversão da prisão domiciliar nos casos concretos, a realidade segue rígida. Na esteira do que propõe Davis (2012), nota-se a centralidade do gênero na punição estatal nas negativas de conversão da prisão preventiva em domiciliar, estas atribuídas ao exercício de uma maternagem não vista como "normal" ou "esperada". Ao alegar "a incompatibilidade da maternidade com o crime", como justificativa para a não concessão do HC, descreve-se a construção do desvio da mulher presa, compreendendo o controle sobre o corpo feminino.

A problemática relaciona-se à necessária reflexão sobre a construção social da categoria de gênero, desde uma perspectiva crítica, e é, neste ponto, que a Criminologia Feminista se mostra fundamental. Justamente, o encontro de gênero com o campo criminológico possibilita "a indagação sobre como o sistema penal trata a mulher" (ANDRADE, 2012, p.127). Compreender que os papéis socialmente construídos sobre essa 
mulher, submetida ao controle informal da família, da igreja, por exemplo, se somam à teia do controle punitivo, faz com que se complexifique o controle social sobre os corpos femininos. Tal perspectiva também é explicitada por Braga (2015) ao analisar as trajetórias de mulheres mães selecionadas pelo sistema penal. Nas palavras da autora

\begin{abstract}
A mulher presa transita entre os papéis de mãe e criminosa, papéis estes que ocupam posições diametralmente opostas na representação do feminino: o primeiro pautado pela maternidade como vocação natural, exclusiva e sacralizada da mulher; e o segundo marcado pelo crime como um desvio das expectativas sociais e morais que recaem sobre quem nasce sob o sexo feminino. (BRAGA, 2015, p. 527).
\end{abstract}

Essa noção de mulher duplamente transgressora se entrelaça ao papel social de cuidado atribuído, historicamente, às mulheres. A elas recai a responsabilidade do trabalho doméstico - não remunerado -, contexto no qual se dá a "naturalização do cuidado como uma tarefa tipicamente feminina que reforça o estereótipo de gênero e pauta a organização familiar de muitas brasileiras, dentro e fora das prisões" (BRAGA, 2015, p. 533). Nesse sentido, o estudo "Saúde materno-infantil nas prisões"13 (LEAL et al, 2016) aponta que um terço das mulheres pesquisadas eram chefes de família; no mesmo sentido, a investigação de Silva (2015) retrata que as dificuldades familiares ganham mais peso com o encarceramento materno, se comparado ao paterno.

Percebe-se, assim, que a prisão afeta não só as vidas dessas mulheres, mas reverbera de forma marcante na rede familiar. A necessidade de aplicação de medidas alternativas à privação de liberdade às mulheres mães, portanto, se mostra ainda mais latente, uma vez que os reflexos do encarceramento feminino ultrapassam os muros das prisões e afetam a vida da família extensa.

Mas não é só. Deve-se levar em conta a premissa de que a prisão preventiva "deve ser excepcional e, no caso das mulheres grávidas e/ou com filhos, a aplicação de medidas desencarceradoras atende à melhor proteção destes segmentos" (SIMAS et al, 2019, p. 53) A excepcionalidade da privação de liberdade prévia à sentença penal condenatória deve ser analisada com seriedade. No contexto em que isolamento social e esvaziamento de instituições penais são imperiosos para a efetiva promoção do direito à saúde, a

13 Nas palavras das autoras, "realizamos o estudo multidisciplinar "Saúde materno-infantil nas prisões", financiado pela Fundação Oswaldo Cruz e Ministério da Saúde, que integrou componente de saúde, psicossociologia, jurídico e arquitetura. O projeto "Saúde materno-infantil nas prisões" foi um censo de base institucional realizado entre Agosto de 2012 e Janeiro de 2014 nas unidades prisionais femininas que abrigavam mães vivendo com seus filhos, localizadas nas capitais e regiões metropolitanas de 24 estados brasileiros e no Distrito Federal." (LEAL et al, 2016, p. 2062). 


\section{ENCARCERAMENTO E COVID19 À LUZ DA CRIMINOLOGIA FEMINISTA: A RECOMENDAÇÃO \\ №62 DO CONSELHO NACIONAL DE JUSTIÇA COMO UM IMPULSO À EFETIVAÇÃO DE DIREITOS \\ FUNDAMENTAIS DE MULHERES MÃES E GESTANTES PRESAS}

excepcionalidade da prisão preventiva se evidencia ainda mais. Na linha de Carvalho e Weingert (2012, p.253)

é necessário afirmar as alternativas à prisão e à internação como efetivas alternativas e não como sistemas adicionais, apêndices ou válvulas de escape do insolvente modelo de privação de liberdade. Devem constituir-se, portanto, como possibilidades reais de minimizar a dor do encarceramento, estabelecendo radical ruptura com a lógica carcerocêntrica.

Por isso, a Recomendação Conjunta do CNJ potencializa aquilo que já previa a legislação relativa a mulheres mães e gestantes, impulsionando que medidas alternativas à privação de liberdade sejam implementadas. Não há dúvida de que, mesmo antes da pandemia, os males gerados pelo aprisionamento já deveriam ser minimizados por medidas desencarceradoras "permitindo condições mais propícias para o desenvolvimento dessas crianças e inserção social de suas mães." (SIMAS et al, 2019, p. 54). Em um contexto de crise sanitária e de saúde, especificamente no que tange a mulheres gestantes e mães, portanto, a implementação de tais medidas, de uma vez por todas, se torna essencial, a fim de que os direitos fundamentais sejam de fato efetivados.

\section{CONCLUSÃO}

Não é possível falar do encarceramento feminino brasileiro sem atentar-se aos estudos de gênero, classe e raça fundamentais para a compreensão desse fenômeno social..Compreender a centralidade do gênero no encarceramento feminino e no sistema punitivo, somente será possível a partir da ótica de um feminismo jurídico e, por consequência, de uma Criminologia Feminista capaz de analisar as questões que envolvem as mulheres dentro do sistema penitenciário brasileiro.

Os presídios brasileiros destacam-se por sua violência e precariedade que se mostram ainda mais devastadores quando se trata de mulheres no cárcere, violando preceitos fundamentais de nossa Carta Magna referentes à dignidade e à humanização na execução das penas. Nesse cenário, mobilizando a perspectiva teórica da Criminologia Feminista, foi possível estudar a situação específica das mulheres mães e gestantes presas em tempos de pandemia (ocasionado pelo novo Coronavírus), buscando analisar em que medida a Recomendaçãon $^{\circ} 62$ do Conselho Nacional de Justiça potencializa e impulsiona a efetivação dos direitos fundamentais dessas mulheres, mais especificamente sobre a conversão da prisão provisória em prisão domiciliar. 
A título conclusivo, o estudo aponta que tal Recomendação ainda pode não ser suficiente para a efetivação dos direitos fundamentais das encarceradas previstos na Constituição Federal, uma vez que as mulheres infratoras, dentro de uma perspectiva de gênero, são vistas como duplamente transgressoras. Isso leva, muitas vezes, a não aplicação de medidas alternativas, em especial a conversão da prisão preventiva em domiciliar prevista na Lei n ${ }^{\circ}$ 13.769/18. Ainda assim, vale ressaltar a importância desta Recomendação em prol da efetivação das medidas alternativas e, consequentemente, nos direitos fundamentais das mães e gestantes.

Nessa senda, desde a perspectiva nacional, a pandemia da Covid19 escancara a falência do sistema prisional - que viola preceitos fundamentais - , especialmente quanto aos atravessamentos entre o sistema punitivo e as construções de papéis sociais. Mulheres mães e gestantes, antes da pandemia, já possuíam seus direitos de conversão de prisão provisória em prisão domiciliar previstos no CPP, com fulcro no texto Constitucional, os quais, muitas vezes, não se tornavam efetivos pelas razões expostas neste artigo. A necessidade de esvaziamento dos estabelecimentos penais recomendada pela Recomendação $n^{\circ} 62$ do CNJ, desde a imperativa ordem de isolamento social, reforça, sem sombra de dúvidas, a necessidade de medidas alternativas à privação de liberdade. Frisa-se, por fim, que tais diretrizes, já direcionadas à população de mulheres mães e gestantes, fortalecem a potencial efetivação dos direitos fundamentais dessas mulheres.

\section{REFERÊNCIAS}

ANDRADE, Vera Regina Pereira de. Pelas mãos da criminologia: o controle penal para além da (des)ilusão. Rio de Janeiro: Revan, 2012.

BASTOS, Douglas de Assis; KRELL, Andreas Joachim. O Estado de Coisas Inconstitucional como ativismo dialógico-estrutural para concretização de direitos fundamentais: limites para o controle judicial de políticas penitenciárias. Direito \& Paz | São Paulo, SP - Lorena | Ano IX | n. 37 | p. 293-308 | 2o Semestre, 2017. Disponível em:

http://www.mpsp.mp.br/portal/page/portal/documentacao_e_divulgacao/doc_biblioteca/bibli_ servicos_produtos/bibli_informativo/bibli_inf_2006/6FC8363C9E2E490CE050A8C0DD017 248. Acesso em: 26 jun 2020.

BARATTA, Alessandro. O paradigma do gênero: Da questão criminal à questão humana. In: CAMPOS, Carmen Hein de (org). Criminologia e Feminismo. Porto Alegre: Sulina, 1999. 


\section{ENCARCERAMENTO E COVID19 À LUZ DA CRIMINOLOGIA FEMINISTA: A RECOMENDAÇÃO \\ №62 DO CONSELHO NACIONAL DE JUSTIÇA COMO UM IMPULSO À EFETIVAÇÃO DE DIREITOS \\ FUNDAMENTAIS DE MULHERES MÃES E GESTANTES PRESAS}

BARATTA, Alessandro. Criminologia crítica e crítica do direito penal: introdução à sociologia do direito penal. 2.ed. Rio de Janeiro: F. Bastos, 1999.

BORGES, Juliana. Encarceramento em massa. São Paulo: Polén, 2019.

BRAGA, Ana Gabriela Mendes. Entre a soberania da lei e o chão da prisão: a maternidade encarcerada.Rev. direitoGV, São Paulo , v. 11, n. 2, p. 523-546, Dez. 2015

BRASIL. Ministério da Justiça. Departamento Penitenciário Nacional. Levantamento Nacional de Informações Penitenciárias. Atualização Junho de 2016. Brasília, 2017. Disponível em: <http://depen.gov.br/DEPEN/noticias-1/noticias/infopen-levantamentonacional-de-informacoes-penitenciarias-2016/relatorio_2016_22111.pdf>

BRASIL. Ministério da Justiça e Segurança Pública. Departamento Penitenciário Nacional. Levantamento Nacional de Informações Penitenciárias (INFOPEN) Mulheres, $2^{\mathrm{a}}$ ed. 2017. Disponível em: <http://depen.gov.br/DEPEN/depen/sisdepen/infopenmulheres/infopenmulheres_arte_07-03-18.pdf $>$

BRASIL, Lei n. 13.257, de 8 de março de 2016. Dispõe sobre as políticas públicas para a primeira infância e altera a Lei no 8.069, de 13 de julho de 1990 (Estatuto da Criança e do Adolescente), o Decreto-Lei no 3.689, de 3 de outubro de 1941 (Código de Processo Penal), a Consolidação das Leis do Trabalho (CLT), aprovada pelo Decreto-Lei no 5.452, de 1o de maio de 1943, a Lei no 11.770 , de 9 de setembro de 2008, e a Lei no 12.662, de 5 de junho de 2012. Disponível em: <http://www.planalto.gov.br/ccivil_03/_Ato2015-

2018/2016/Lei/L13257.htm> . Acesso em: out. 2018.

BRASIL, Lei n. 13.769. Lei n. 13.769, de 19 de dezembro de 2018. Altera o Decreto-Lei no 3.689, de 3 de outubro de 1941 (Código de Processo Penal), as Leis $n^{\circ} 7.210$, de 11 de julho de 1984 (Lei de Execução Penal), e 8.072, de 25 de julho de 1990 (Lei dos Crimes Hediondos), para estabelecer a substituição da prisão preventiva por prisão domiciliar da mulher gestante ou que for mãe ou responsável por crianças ou pessoas com deficiência e para disciplinar o regime de cumprimento de pena privativa de liberdade de condenadas na mesma situação. Disponível em: <http://www.planalto.gov.br/ccivil_03/_Ato2015-

2018/2018/Lei/L13769.htm>

BRASIL. Supremo Tribunal Federal. Arguição de Descumprimento de Preceito Fundamental No 347/DF. 2015. Disponível em:

http://redir.stf.jus.br/paginadorpub/paginador.jsp?docTP=TP\&docID=10300665. Acesso em: 26 jun 2020.

CENTRO DE APOIO OPERACIONAL DAS PROMOTORIAS - MPPR. Maternidade no Cárcere e Lei n. 13.769/2018 Apontamentos sobre a prisão domiciliar como substituto da prisão preventiva e do regime de cumprimento de pena e como instrumento da progressão especial de regime. Paraná: fev. 2019. P. Disponível em:

<http://www.criminal.mppr.mp.br/arquivos/File/Maternidade_no_Carcere_e_Prisao_domicili ar_-_versao_2019__-versao_atualizada_em_26-2-2019.pdf> 
CONSELHO NACIONAL DE JUSTIÇA (CNJ). Recomendação $\mathbf{N}^{\circ} \mathbf{6 2}$, de 17 de março de 2020. Disponível em: <https://www.cnj.jus.br/wp-content/uploads/2020/03/62Recomenda\%C3\%A7\%C3\%A3o.pdf>. Acesso em: 22 maio 2020.

DINIZ, Débora. Cadeia: relatos sobre mulheres. Rio de Janeiro: Civilização Brasileira, 2015.

DAVIS, Angela. Estarão Obsoletas as prisões? Rio de Janeiro: DIFEL, 2018, p. 65-89. Disponível em:

<http://www.susepe.rs.gov.br/conteudo.php?cod menu=203\&cod conteudo=3829>

DIUANA, Vilma et al. Direitos reprodutivos das mulheres no sistema penitenciário: tensões e desafios na transformação da realidade. Ciênc. saúde coletiva [online]. 2016, vol.21, n.7, pp.2041-2050. ISSN 1413-8123. Disponível em: <http://dx.doi.org/10.1590/1413$\underline{81232015217.21632015>\text {. }}$

GONÇALVES, Vanessa Chiari. A Prisão Domiciliar com Monitoramento Eletrônico como Alternativa ao Regime Semiaberto: a experiência da Comarca de Porto Alegre. Revista Brasileira de Ciências Criminais. São Paulo: RT, vol. 143, ano 26, p. 221-244, maio 2018.

INSTITUTO ALANA. Pela liberdade: a história do habeas corpus coletivo para mães \& crianças. São Paulo: Instituto Alana, 2019. Disponível em:

$<$ https://prioridadeabsoluta.org.br/wp-content/uploads/2019/05/pela liberdade.pdf>. Acesso em: 07 jun 2020.

INSTITUTO TERRA, TRABALHO E CIDADANIA. MaternidadeSemPrisão: diagnóstico da aplicação do Marco Legal da Primeira Infância para o desencarceramento de mulheres. São Paulo : ITTC, 2019. Disponível em: http://ittc.org.br/wpcontent/uploads/2019/10/maternidadesemprisao-diagnostico-aplicacao-marco-legal.pdf. Acesso em: 21 jun 2020.

LEAL, M. C. et al. Nascer na prisão: gestação e parto atrás das grades no Brasil. Ciência \& Saúde Coletiva, v. 21, n. 7, 2016. Ciência \& Saúde Coletiva, 21(7):2071-2079, 2016.

LARRAURI, Elena. Género e Derecho Penal. 1994. Disponível em:

http://www.cienciaspenales.net/files/2016/09/5generoyderechopenal11.elenalarrauri.pdf

MENDES, Soraia da Rosa. Criminologia feminista novos paradigmas. São Paulo Saraiva. 2017. 2 recurso online (IDP). ISBN 9788547221706.

MENDES, Soraia da Rosa. Processo Penal Feminista. 1. ed. - São Paulo: Atlas, 2020.

RIO GRANDE DO SUL. Tribunal Regional de justiça. Habeas Corpus 70081028706. Relator Honório Gonçalves da Silva Neto. 2019. Disponível em: <http://www.tjrs.jus.br/site/buscasolr/index.html?aba=jurisprudencia.> . Acesso em: 18 set. 2019.

SILVA, Amanda Daniele. Mãe/mulher atrás das grades: a realidade imposta pelo cárcere à família monoparental feminina. São Paulo: Cultura Acadêmica, 2015. 


\section{ENCARCERAMENTO E COVID19 À LUZ DA CRIMINOLOGIA FEMINISTA: A RECOMENDAÇÃO №62 DO CONSELHO NACIONAL DE JUSTIÇA COMO UM IMPULSO À EFETIVAÇÃO DE DIREITOS \\ FUNDAMENTAIS DE MULHERES MÃES E GESTANTES PRESAS}

SILVA, Salete Maria da. Feminismo Jurídico: Uma introdução. Revista Cadernos de Gênero e Diversidade - UFBA, vol 04, n. 01 - Jan. - Mar., 2018. Disponível em: https://portalseer.ufba.br/index.php/cadgendiv

SIMAS, Luciana et al. Saúde materna e infantil nas prisões: contribuições para o habeas corpus coletivo 143/641. In: Pela liberdade: a história do habeas corpus coletivo para mães \& crianças, p. 48-55. São Paulo: Instituto Alana, 2019.

SMART, Carol. El Derecho en el Género y el Género en el Derecho. Tradução ao espanhol: Marta Castillo. Disponível em:

http://derechopublico.pbworks.com/w/file/fetch/58932808/Carol\%20Smart\%20\%20El\%20Derecho\%20en\%20el\%20G\%C3\%A9nero\%20y\%20el\%20G\%C3\%A9nero\%20en \%20el\%20Derecho\%20Pg\%2031\%20a\%2072.pdf

SOUZA, Jessé. A construção social da subcidadania: para uma Sociologia Política da modernidade periférica. Belo Horizonte: UFMG, 2003.

WEIGERT, Mariana de Assis Brasil; CARVALHO, Salo. Criminologia feminista com criminologia crítica. Revista Direito e Práxis, Ahead of Print, Rio de Janeiro, 2019. Disponível em: link para o artigo. acesso em xxxx. DOI: 10.1590/2179-8966/2019/38240

ZAFFARONI, Eugênio Raúl. La mujer y el poder punitivo. Disponível em: <http://www.biblio.dpp.cl/biblio/DataFiles/14202.pdf> 